\title{
Diaspora Komunitas Tamil di Sumatera Utara: Antara Menjadi India atau Indonesia
}

\author{
Suryo Adi Sahfutra, \\ Universitas Pembangunan Panca Budi \\ Email Corresponding author: suryoadi@dosen.pancabudi.ac.id
}

\begin{abstract}
Cultural sustainability refers to inter-and intra-generation access to cultural heritage. The sustainability of non-material culture is complex because it is related to the experiences of cultural groups and is built by actors in their daily lives. Cultural sustainability is important for the diaspora community because it is an attempt to maintain their cultural identity in their communities while not completely losing contact with cultural elements in their ancestral lands. This paper discusses the strategies used by Muslim Tamils in Medan, North Sumatra, The Muslim Tamils in Indonesia use mainly informal strategies in the process of preserving culture. However, technological advances that have increased the ease of travel and communication have also enhanced the communication and closeness of these two communities with other Tamil communities around the world and have helped further the sustainability of art, language, culinary and religious practices. Muslim Tamils in Medan are experiencing a crisis of identity as Tamils because they are Muslim and many cultural identities conflict with Islamic teachings. Cross-ethnic marriage, assimilation with the nonTamil community is strong enough to influence changes in cultural orientation, the identity that is still embedded in the Tamil Muslim community can only be found in weddings, culinary and some cultural adaptation practices. At the same time, as citizens of descent, they face the construction of a citizenship identity, becoming Tamils who live in Indonesia or become Indonesians as ethnic Tamils.
\end{abstract}

Keywords: cultural sustainability, muslim Tamil diaspora, North Sumatera

\section{PENDAHULUAN}

Komunitas Tamil di Indonesia sudah ada sejak masa pra kolonialisme (Sandhu \& Mani, 1993, pp. 87-88), keberadaan mereka disebabkan adanya migrasi dari wilayah Asia Selatan seperti India, khususnya wilayah India Selatan, Sri Langka dan beberapa wilayah lainnya (Sandhu \& Mani, 1993). Perkembangan etnis Tamil banyak ditemukan di beberapa wilayah di Asia Tenggara, seperti Singapura, Malaysia dan Indonesia (Mujani, 2012). Sebagaian besar kelompok ini sudah berdomisili sejak lama dan bergenerasi. Namun ada juga yang datang belakang sejak mobilitas dan konektivitas lintas negara semakin meningkat, khususnya wilayah Asia Tenggara.

Sebagai salah satu etnis yang tersebar di berbagai wilayah di dunia, komunitas tamil senantiasa berhasil beradaptasi dan bertahan dari berbagai kesulitan yang dihadapi sebagai kelompok minoritas, pendatang dan warga keturunan. Sebagai sebuah etnis yang sangat mudah diidentifikasi secara kasat mata, kehidupan diaspora komunitas Tamil pada awalnya cenderung berkelompok (Barth, 1969).

Istilah Tamil Muslim merujuk kepada etnis Tamil yang beragama Islam. Istilah ini banyak ditolak oleh orang Tamil Muslim sendiri. Namun menggunakan istilah lain seperti India Muslim akan terjebak pada generalisasi India sebagai bangsa yang memiliki beragam etnis. 
Di Sumatera utara khususnya di kota Medan, kelompok ini sudah ada sejak abad 18 akhir, yaitu pada masa kesultanan deli yang dipimpin oleh Sultan Makmun Ar Rasyid (Mujani, 2012, pp. 1348-1353). Jalinan hubungan antara kesultanan deli dengan komunitas Tamil Muslim dipengaruhi oleh dua bentuk jalinan, yaitu jalinan sebagai sesama muslim, dalam hal ini kesultanan deli memberikan bantuan berupa tanah untuk berdomisili sekaligus tempat membangun masjid. Jalinan kedua adalah antara majikan dan buruh, kelompok mayoritas Tamil bekerja diperkebunan milik Kesultanan Deli (Perret, 2010, p. 39).

Perkembangan etnis Tamil Muslim di kota Medan dapat dibaca sebagai bagian dari etnis Tamil secara umum. Meskipun terdapat perbedaan yang cukup mencolok, kelompok Tamil Muslim dalam hal mempertahankan identitas sebagai etnis Tamil menghadapi masalah yang serius. Identitas sebagai Tamil pada satu sisi, sebagai muslim di sisi yang berbeda dan pada saat yang sama sebagai warga keturunan dengan kewarganegaraan Indonesia. Jalinan ketiga variabel identitas tersebut didialogkan secara berkelanjutan. Mayoritas orang-orang Tamil muslim adalah warga keturunan, artinya mereka sudah lahir dan tumbuh di Medan, menggunakan bahasa indonesia lebih dominan daripada bahasa tamil. Berintegrasi dengan non tamil di sekolah, pernikahan, tempat kerja dan jalinan hubungan profesionalitas lainnya.

Diaspora Tamil Muslim membentuk satu pola tersendiri dari diaspora Tamil yang mayoritas Hindu, sebagaian kecil Budha dan Katolik. Mereka hanya diikat oleh identitas sebagai etnis Tamil, sebuah identitas yang dalam proses dialektika kulturalnya banyak ditolak oleh kelompok Tamil Muslim. Penolakan tentu karena adanya politik generalisasi, bahwa Tamil identik dengan Hindu, asosiasi yang mengusik identitas keislaman orang Tamil Muslim. Lantas bagaimana Tamil muslim mengidentifikasi dirinya dan komunitasnya dalam perebutan identitas etnis? Bagaimana kelompok ini mempertahankan kebudayaannya? Ditengah geliat multikulturalitas yang sedang menguat dengan memunculkan politik identitas berbasis penguatan nilai-nilai kultural.

Globalisasi yang diikuti oleh kuatnya mobilitas, konektivitas antar wilayah dan antar negara menjadikan akses sebaran informasi serta tingkat keterhubungan antara satu identitas kebudayaan yang sama atau bahkan berbeda semakin membangkitkan kesadaran kolektivitas komunitas (Giddens, 2003). Identitas kultural menjadi penting karena ia menjadi politik pembeda seperti agama, ras dan etnis. Transnasionalisme budaya yang menyebar membangkitkan memori tentang sejarah asal, identitas asal dengan segala macam konstruksi masa lalu yang masih tersisa sampai saat ini, bahasa, seni, kuliner serta warisan historis yang sangat mudah untuk ketahui (Waters, 1995).

Masyarakat diaspora memiliki kecenderungan tiga hal, seperti misalnya yang diuraikan aleh Vertovec, yaitu: proses penyebaran, masyarakat di mana komunitas itu tinggal, tempat atau ruang geografis di mana komunitas ini berada. Dari sudut pandang siologis dan antropologis masyarakat diasporik mengalami perubahan yang disebabkan oleh interaksi dan proses adaptasi dengan masyarakat lokal. Perubahan terkait kedatangan dan posisi sebagai minoritas akan berdampak pada bentuk organisasi dan mobilisasi, politik pengakuan, kedudukan perempuan, regenerasi, etnis dan keragaman agama, identitas dan kemasyarakatan, ritualisme, respasialisasi, jaringan: horisontal-vertikal, kesadaran identitas kegamaan global, lokalitas versus universalitas, reorientasi pengabdian dan lintasan (Vertovec, 2004).

Diaspora sebagaimana dikutip dari Baumann oleh Vertovec, menunjukkan tiga titik referensial yaitu: a) proses penyebaran; b) kehidupan sebagai pendatang (asing); c) geografis atau tempat di mana kelompok diaporik hidup menyebar. Sementara itu ciri-ciri umum masyarakat diaspora antara lain adalah: relasi sosial yang diperkuat dengan ikatan sejarah dan geografi asal dan ketegangan orientasi politik masyarakat diasporik yakni antara kesetiaan negara asal dengan status warga negara di mana mereka tinggal (Vertovec, 1999, p. 4). 
Komunitas diaspora Tamil Muslim di kota Medan turut serta menghadapi dinamika seperti yang diuraikan oleh Vertovec, namun konteks tersebut lebih dominan terjadi dikalangan komunitas Tamil Hindu, karena keterhubungan budaya dan agama sekaligus dengan wilayah asal. Sementara komunitas Tamil Muslim mengalami keterputusan jarak psikologis dan memori historis dengan daerah asal yang berkaitan dengan budaya dan agama.

Menjadi muslim di Indonesia adalah keberuntungan psikologis sekaligus kultural, setidaknya karena logika mayoritanisme masih begitu kuat. Artinya, komunitas Tamil Muslim mendapatkan 'keistimewaan' karena identitas keislamannya. Disamping 'keistimewaan' yang didapat tentu ada juga konsekwensinya bagi identitas etnisnya, dalam konteks ini ke-tamilannya akan tersisihkan oleh dominasi identitas kemuslimannya. Resiko ini disebabkan oleh bentuk keislaman yang dipilih atau dengan kata lain, model Islam yang dikembangkan oleh komunitas Muslim Tamil bercorak formal, menolak sinkretisme agama dan budaya, sehingga budaya Tamil yang dianggap bertentangan dengan Islam akan disingkirkan.

Menariknya, imajinasi tentang wilayah asal-asul, keberlanjutan tradisi dan budaya, menjadi isu yang mulai mengusik Tamil Muslim karena masyarakat lokal begitu kuat memunculkan tradisi lokalitasnya. Keinginan melebur dalam kultur baru, tidak memungkinkan disebabkan identitas etnik, sementara ingin menunjukkan identitas Tamil terbentur karena keidentikkan budaya tamil dengan Hindu begitu kuat, akhirnya organisasi modern sebagai asosiasi ke-Tamil-lan dibentuk dengan tidak melabelinya dengan identitas Tamil melainkan identitas India.

\section{Antara 'New Delhi' dan Tanah Deli}

Tamil sebagai mana dikenal luas, adalah etnis yang tidak memiliki negara, berkembang dan menyebar dibanyak wilayah dibelahan dunia. Identifikasi secara fisik etnis Tamil cukup mudah, karena warna kulit dominan gelap, hidung mancung dan pakaian yang khas india. Kendati demikian, etnis Tamil berdiaspora keberbagai penjuru dunia sudah sejak lama, di provinsi Sumatera Utara jejak orang Tamil dapat ditelusuri pada awal abad 19 ketika perkebunan Deli membutuhkan buruh pekerja.

Beberapa studi menjelaskan bahwa kenapa buruh banyak didatangkan dari wilayah India Selatan atau etnis Tamil baik itu di Malaysia, Penang maupun di Sumatera Timur kala itu, para sarjana berargumen bahwa populasi penduduk khususnya di wilayah Asia Selatan cukup besar, dan angka pengangguran yang disebabkan keterbatasan keahlian, tidak terdidik menjadikan mereka mudah untuk 'dikelabui' (Mujani, 2012).

Kedatangan Tamil Muslim menurut beberapa sarjana hampir bersamaan dengan kedatangan Tamil Hindu, mereka bekerja sebagai buruh perkebunan, meskipun ada catatan sejarah yang bersumber dari arkeologi semacam prasasti yang diidentifikasi sebagai bukti kedatangan orang India Muslim pertama kali ke wilayah Sumatera, khususnya di Barus (kota purba) dipinggir pantai Samudra Hindia (Mujani, 2012). Catatan itu di duga berasal dari Gujarat India sebagaimana banyak tesis yang menyebutkan awal kedatangan Islam di Indonesia berasal dari Gujarat India. Namun prasasti itu sebagai tanda kedatangan dalam urusan dagang, bukan berdiaspora. Sehingga di lokasi ditemukannya prasasti tidak ada komunitas India.

Menurut Luckman Sinar (2008) kedatangan awal India muslim ke wilayah sumatera berasal dari wilayah Malabar yang bermazhab Syafi'i sekitar tahun 717 Masehi (Sinar, 2008, p. 1). Tidak jelas sumber yang dipakai untuk menguatkan argumentasi itu. Menurut analisis A. Mani setidaknya terdapat 100 orang muslim Tamil pada awal-awal kedatangan di Sumatera yang bekerja diperkebunan Deli (Sandhu \& Mani, 1993, p. 89). Kelompok ini berasal dari India Selatan bersuku Tamil. Mani mengatakan bahwa komunitas Muslim Tamil bekerja tidak hanya disektor perekebunan, melainkan juga menjadi pedagang, ada yang 
berdagang kain, dan menjadi pejahit baju. Tempat tinggal mereka awalnya tersebar di beberapa titik,setelah perkebunan deli berakhir dengan ditandainya Indonesia merdeka, banyak orang Tamil, termasuk juga kelompok muslim Tamil memilih menentap di Medan, dan ada juga yang kembali ke daerah asal (Sandhu \& Mani, 1993, p. 89).

Tanah Deli menjadi tempat baru bagi diaspora komunitas Muslim Tamil, kendala kultural termasuk didalamnya bahasa, menjadikan mereka bermukim secara kelompok. Seperti sejarah asal mula berdirinya kampung Kling, yang saat ini berada di pusat kota Medan dan berubah nama menjadi kampung Madras adalah tanah pemberian dari kesultanan Deli, alasan pemberian tanah tersebut agar komunitas Tamil Muslim dapat mendirikan Masjid untuk beribadah salat jum'at dan lainnya (Sinar, 2008). Kesulitan beribadah karena kendala bahasa menjadikan kesultanan bersedia menghibahkan tanahnya.

Komunitas Tamil Muslim kemudian banyak yang berdomisili di wilayah tersebut, uniknya tanah yang diberikan sultan berdekatan dengan komunitas Tamil Hindu. Tidak jauh dari lokasi tersebut berdiri kuil Shri Mariaman, salah satu kuil Hindu tertua di Sumatera Utara. Di kawasan yang saat ini menjadi pusat perdagangan terdapat dua masjid, yaitu masjid Gaudiyah dan masjid Jami', dua masjid sebagai bukti eksistensi komunitas Tamil Muslim di tanah Deli diawal-awal perkembangannya.

Diaspora komunitas Muslim Tamil kemudian mendirikan sebuah yayasan sebagai wadah menaungi warga muslim yang berasal dari India Selatan, yaitu South Indian Moslem Foundation and Welfare Committee, berdiri pada tahun 1887. Yayasan ini berperan penting dalam mempertahankan eksistensi komunitas muslim India Selatan yang ada di Sumatera Utara. Yayasan ini menjadi penghubung memori sejarah tentang tanah leluhur, penguat identitas budaya dan ruang dialogis atas berbagai persoalan yang dihadapi sebagai komunitas diaspora.

Tanah Deli telah banyak memberikan identitas baru bagi orang Tamil, tak terkecuali mereka yang beragama Islam. Di tanah ini mereka membangun identitas, melestarikan budaya dan beradaptasi dengan perubahan 'cuaca' perkembangan masyarakat. Di Medan kita bisa menyaksikan tanah Deli dengan corak 'New Delhi'. Artinya, keberdaan komunitas Tamil secara umum telah menjadi bagian penting dalam perjalanan sejarah etnis di Sumatera Utara. Tak bisa dipungkiri sebagai komunitas diaspora, etnis Tamil telah dan sedang mencari bentuk penyesuaian dengan kondisi sosial, budaya, ekonomi dan politik di Indonesia.

Sebuah laporan menyebutkan bahwa penduduk Tamil yang berjumlah kira-kira 30.000 jiwa di Medan dan sekitarnya, terbagi atas $66 \%$ yang menganut agama Hindu, $28 \%$ agama Budha, 4,5 \% beragama Katolik dan Kristen, dan 1,5\% yang beragama Islam (Napitupulu, 1992). Dalam sebuah wawancara dengan Pastor James Bharataputra (Juli, 2003), pimpinan Graha Anne Maria Velankanni di Medan, disebutkan bahwa jumlah umat Tamil Katolik di kota Medan saat ini kira-kira 800 orang (Lubis, 2005, pp. 163-164).

\section{Menjadi Muslim, Tamil dan Orang Indonesia}

Diaspora muslim Tamil di kota Medan memiliki kemiripan dengan berbagai komunitas diaspora lainnya diberbagai belahan dunia sebut saja misalnya yang terdekat, Malaysia dan Singapura. Hanya konteks sosial politik yang membedakan bentuk-bentuk adaptasi dan perkembangannya. di Indonesia secara umum, orang-orang Tamil muslim cukup mudah beradaptasi dari segi identitas keagamaan, namun menghadapi kesulitan dalam hal beradaptasi dari segi identitas kultural.

Kemudahan adaptasi sebagai kelompok diaspora di wilayah yang moyoritas berpenduduk muslim menjadi 'bonus' tersendiri bagi komunitas Tamil Muslim. Di kota Medan, banyak orang-orang Tamil Muslim yang terintegrasi dengan masyarakat asli, tidak terlalu sulit bagi mereka untuk bisa bergaul dengan masyarakat, bekerja dibidang yang tidak 
hanya dirinya sendiri orang Tamil, berdomisili di lingkunan mayoritas non Tamil, anak-anak sekolah di sekolah umum, yang didalamnya orang Tamil tidak lebih dari 3 siswa, misalnya dan begitu seterusnya.

Adaptasi menjadi kata kunci dalam masyarakat diaspora, suka atau tidak, untuk bisa bertahan dalam tekanan kultural tanpa kelompok yang solid, identitas budaya akan mudah tercerabut hilang tanpa jejak. Ikatan solidaritas kelompok menjadi penting dalam mempertahankan identitas kultural. 'Bonus' sebagai muslim bagi orang Tamil bukan tanpa konsekuwensi kultural, kelompok ini tidak mampu menjaga hibriditas tamil dalam konteks persilangan menjadi muslim dan tamil pada diri yang sama.

Marginalisasi budaya dimulai dari keengganan disebut sebagai orang Tamil. Identifikasi sebagai orang Tamil akan berimplikasi teologis, yakni sama dengan orang Hindu, konstruksi semacam itu dalam konteks masyarakat Indonesia memberikan efek relasi sosial yang berbeda, seperti halnya keengganan orang Mandailing disebut Batak karena berasosiasi dengan Kristen (Pelly, 1983). orang Tamil Muslim lebih senang disebut India, meskipun ketika ditanya etnisnya apa, mereka tidak bisa menolak disebut sebagai Tamil (Perret, 2010, p. 39). Bagi mereka, sebutan adalah bagian dari strategi penegasian identitas yang penting dalam melawan generalisasi dan perebutan ruang dominasi dalam narasi identitas.

Dari banyak informan muslim Tamil yang saya wawancarai secara mendalam mengakui hal itu, mereka menghadapi krisis identitas budaya, kehilangan identitas budaya ditengah masyarakat yang menunjukkan gejala penguatan identitas kultural adalah musibah. Mereka kebingungan ketika harus merujuk aktivitas budaya dalam momen-momen tertentu, sekalipun hanya sebatas simbolik semata. Seperti yang diuraikan Yasser, seorang mahasiswa di UIN Sumatera Utara yang bersuku India Tamil.

"dikeluarga kami sudah tidak ada yang bisa bahasa India (Tamil) karena kami tinggal di wilayah yang orang indianya hanya keluarga kami sendiri. Adat budaya juga saya tidak paham, karena budaya india identik dengan Hindu. Jadi, ya sebenarnya kami sudah tidak bisa disebut sebagai orang India lagi. Paling hanya warna kulit saja yang masih melekat. "(wawancara dengan Muhammad Yasser, Juni 2018).

Krisis identitas budaya yang dialami orang-orang Tamil Muslim disebabkan oleh ketidakmampuan kelompok ini dalam akulturasi antara budaya dan agama, identitas muslim yang melekat kuat akan menegasikan identitas budaya. Ini tentu berbeda dengan Islam dalam konteks masyarakat indonesia yang disebut Islam tradisional, kelompok islam yang mampu mendialogkan identitas budaya dengan agama, sehingga menghasilkan akulturasi budaya Islam lokal.

hal semacam ini tidak terjadi dikalangan Tamil Muslim, karena corak Islam yang diamalkan oleh kebanyakan mereka adalah Islam salafi, yakni satu model pengamalan ajaran Islam yang bersandar pada generasi awal Islam. Menurut paham ini, hal-hal yang bersifat kultural harus dijauhkan dari ajaran Islam karena tidak pernah diajarkan Nabi atau para sahabat.

Jika ditelusuri corak keberagamaan Tamil Muslim yang ada di Medan didominasi oleh corak Islam Jemaah tablig (Esposito, 2001, p. 36). Jemaah Tablig memang lebih dekat secara psikologis dengan komunitas Tamil Muslim karena sejarah dan teritorial kawasan di mana munculnya gerakan Jemaah Tablig juga dari India. Karakter Jemaah Tablig tidak 'ramah' dengan tradisi memiliki andil dalam proses marginalisasi budaya dikalangan etnis Tamil Muslim. Kuatnya dominasi Jemaah Tablig karena jejaring orang Tamil Muslim juga kuat didalamnya. Yayasan komunitas muslim India Selatan misalnya, memiliki jaringan kuat dengan kelompok Jemaah Tablig (Esposito, 2001, p. 36). 
Kesadaran tentang identitas budaya asal muncul sejak satu dekade terakhir, saat konektivitas dengan daerah asal mengalami peningkatan. Khususnya perjumpaan dengan orang-orang Tamil yang baru tiba dari negeri asal datang ke Medan. Mereka mulai mempertanyakan identitas budaya komunitas diaspora Tamil Muslim, mulai dari aspek simbolik, seperti pakaian, kuliner hingga yang paling mudah ditelaah, yaitu bahasa. Mereka sering mendapatkan ledekan seperti misalnya ketika menjalin hubungan dagang, 'kamu orang India, mana bahasamu!, kamu harus bisa bahasa aslimu' (wawancara dengan Sarifah Radiyah, Juli 2018). Stigma kehilangan identitas kultural memang tidak mengenakkan bagi sebahagian mereka.

Aspek kultural yang tercerabut dari identitas sebagai orang Tamil lainnya adalah pemberian nama pada anak. Orang Tamil yang menjadi muallaf, akan punya dua nama, nama Tamil dan nama Islam. Sementara anak-anak yang lahir dari orang tua muslim akan diberi nama Arab. Jika anak hasil dari perkawinan dengan penduduk lokal, maka juga akan berdampak pada pemberian nama anak. beberapa keluarga yang murni Tamil Muslim masih ada yang mempertahankan nama keluarga berdasarkan garis keturunan, namun tidak sedikit yang menghilangkan identitas nama sebagai bagian dari identitas kultural.

Lagi-lagi penghilangan identitas kultural dalam nama seseorang karena keengganan diidentifikasi sebagai orang Tamil yang identik dengan Hindu. Fakta ini tidak menunjukkan adanya ketegangan yang kuat antara Tamil Hindu dengan Tamil Muslim, khususnya dalam perebutan identitas budaya, melainkan sebatas konstruksi teologis. Banyak orang Tamil Muslim sudah terputus jaringan dengan wilayah asal (the countries of origin) sebagai salah satu unsur penyebab adanya kekaburan budaya. Berbeda dengan Tamil Hindu yang berkelanjutan menjalin kontak dengan keluarga, kolega dan orang-orang dari wilayah asal.

Persilangan budaya melalui pernikahan ini menarik, sulit menemukan pasangan Hindu Tamil dengan orang lokal, sementara cukup mudah menemukan pasangan Tamil Muslim dengan orang lokal. Kuat dugaan saya, kenapa Hindu Tamil memilih menikah dengan pasangan yang sama identitas kulturalnya, karena alasan benturan budaya dan aspek lingkungan sosial yang dominan sama. Sementara Tamil Muslim menikah dengan non Tamil lebih didasari hasil dari interaksi dengan lingkungan sosial yang berbeda, kemudahan adaptasi budaya khususnya karena kesamaan agama.

Anak-anak yang lahir dari persilangan budaya, mereka yang saat ini memasuki fase remaja mulai memahami identitas kulturalnya. Misalnya, ayah Tamil, Ibu Padang, seperti keluarga Muslim Kumar Krisna Murti, seorang laki-laki mualaf yang menikah dengan perempuan Minang. Identitas kultural yang dominan Tamil bagi anak, mengharuskan sang anak paham bahwa ia adalah orang Tamil yang berasal dari India. Pemahaman yang demikian melingkupi persoalan kebudayaan, mulai dari bahasa, seni dan hal-hal keseharian (wawancara dengan Kumar Krisna Murti, Juli 2018). Uniknya, sang anak secara perlahan mulai mencari tahu tentang hal-hal yang berkaitan dengan etnisnya, asal muasal leluhurnya. Dari sini imajinasi nasionalisme muncul, ia merasa sebagai orang India (nation), tapi pada saat yang sama ia adalah orang Indonesia.

Yang tersisa dari eksistensi budaya Tamil Muslim di kota Medan berada pada dua aspek. Pertama, aspek kuliner, orang-orang Tamil Muslim belum bisa sepenuhnya meninggalkan makanan khas Tamil, khususnya bumbu-bumbu masakan dan jenis-jenis makanan khas tradisional. Pada momen tertentu, seperti perkumpulan komunitas seperti pengajian, pesta pernikahan dan hari besar Islam, kuliner yang mereka sajikan selalu khas Tamil (wawancara dengan Sarifah Radiyah, Juli 2018). Kedua, pakaian adat. Pakain yang dimaksud adalah kain sari bagi perempuan, di pesta pernikahan pakain sari yang dikenakan oleh wanita Tamil dikombinaskan dengan hijab, jilbab dan pakaian muslim. Pakain menjadi identitas penting yang masih dipertahankan oleh perempuan Tamil Muslim karena hal ini 
masih dapat dinegosiasikan dengan ajaran Islam dalam menutup aurat (wawancara dengan M. Soleh Siddiq, April 2017).

Dalam konteks politik lokal, identitas Tamil Muslim sempat digaungkan ketika gubernur Sumatera Utara dipimpin oleh Syamsul Arifin, gubernur terpilih priode 2008-2011, keturunan campuran Melayu-Tamil. Setiap momentum puasa ramadhan tiba, selalu ada acara buka puasa bersama dengan menu khas india Tamil di Masjid Jami' atau masjid Ghaudiyah yang diprakarsai oleh Syamsul. Ia juga pernah menginisiasi perkumpulan Tamil Muslim Sumatera Utara, tapi kasus korupsi memaksanya melepaskan jabatan gubernur menjadikan rencana tersebut tida berjalan (wawancara M. Siddiq Mubarak, Juli 2018).

dalam konteks nasional, diaspora Tamil Muslim yang lahir sebagai generasi ke tiga, lebih dominan merasa menjadi orang Indonesia, sementara Tamil hanya sebatas identitas etnik. Pemahaman tentang memori sejarah leluhur banyak yang tidak mahu tahu dan cenderung acuh. Identitas kultural tidak begitu penting bagi generasi ini, disebabkan perjumpaan dengan banyak orang-orang yang sama-sama diaspora, khususnya yang tinggal di kawasan kota Medan, yakni etnis Tionghoa. Jadi, perbincangan tentang leluhur sangat jarang ditemukan. Lain halnya jika mereka tinggal berdekatan dengan komunitas diaspora Tamil Hindu, interaksi sesama tamil dan berbeda agama menjadikan mereka harus paham seluk beluk budaya tamil, paling tidak bahasa sebagai alat komunikasi sehari-hari.

\section{KESIMPULAN}

Problem paling mendasar yang sering dihadapi komunitas diaspora muslim diantaranya adalah kehidupan minoritas di masyarakat mayoritas (among minority group). Kedua, penerimaan dan keterbukaan negara tuan rumah (the receiving countries) ada yang mudah beradaptasi ada juga yang tidak mudah dikarenakan masalah benturan masa lalu. Ketiga, konektivitas antara masyarakat diaspora dengan daerah asal (the countries of origin) hubungan ini menjadikan dilematis antara menjadi warga negara secara totalitas namun ada jarak psiko-kultral dengan negara asal.

Diaspora Tamil Muslim di Kota Medan generasi kedua dan ketiga cenderung menghadapi persoalan pencarian bentuk identitas budaya yang cocok dengan model keislaman yang mereka yakini, antara bentuk lama budaya Tamil yang dianggap tidak compatable dengan Islam dan dengan bentuk baru hasil dari akulturasi antara berbagai variabel dalam narasi keberlanjutan budaya.

Sejauh ini, komunitas diaspora Tamil Muslim lebih memilih mengikuti pola konstruksi mayoritas di mana mereka hidup, jika mereka hidup hasil dari persilangan budaya, maka yang dominan membentuk mereka adalah budaya yang dominan ada ditengah kehidupan sehari-hari. Keberlanjutan identitas budaya tamil menjadi dilematis mana kala masyarakat mengidentifikasi mereka sebagai orang Tamil yang tidak paham budayanya, pada saat yang bersamaan mereka menolak diasosiasikan sebagai tamil, melainkan lebih nyaman disebut India. Pertemuan antara menjadi muslim, Tamil dan Indonesia dalam tubuh yang sama tidak mudah bagi keberlanjutan budaya yang terus terkikis.

\section{DAFTAR PUSTAKA}

Barth, F. (1969). Ethnic Grouops and Boundaries, The Social Organization of Culture Difference. Illinois: Waveland Press.

Esposito, J. L. (2001). Jama'ah Tabligh”, dalam Ensiklopedi Oxford Dunia Islam Modern, (jilid 4; D. Eva Y.N, dkk., ed. Ahmad Baiquni, Trans.). Bandung: Mizan.

Giddens, A. (2003). Runaway World Bagaimana Globalisas Merombak Kehidupan Kita. 
Jakarta: Gramedia Pustaka Utama.

Lubis, Z. B. (2005). Kajian Awal Tentang Komunitas Tamil dan Punjabi di Medan: Adaptasi dan Jaringan Sosial. ETNOVISI: Jurnal Antropologi Sosial Budaya, 1(3).

Mujani, W. K. (2012). The History of the Indian Muslim Community in Malaysia. Journal Advances in Natural and Applied Sciences, 6(8).

Pelly, U. (1983). Urban Migration and Adaptation in Indonesia: A Study of the Minangkabau and the Mandailing Batak Migrants in Medan, North Sumatra. University of Illinois.

Perret, D. (2010). Kolonialisme dan Etnisitas: Batak dan Melayu di Sumatera Timur Laut. Jakarta: KPG.

Sandhu, K. S., \& Mani, A. (1993). Indian Communities in Southeast Asia (Indian in; A. Mani, Trans.). Singapore: ISEAS.

Sinar, T. L. (2008). Orang India di Sumatera Utara (The Indians in North Sumatra). Medan: Forkala Sumut.

Vertovec, S. (1999). Three Meanings of "Diaspora": Exemplified among South Asian Religions. London: Oxford University Press.

Vertovec, S. (2004). Religion and Diaspora, dalam Peter Antes, Armin W. Geertz, Randi R.Warne, New Approaches to Study of Religion, volume 2: Textual, Comparative, Sociological and Cognitive Approach. Berlin: de Gruiter GmbH \& Co.

Waters, M. (1995). Globalization (2nd ed.). London: Taylor and Francis Group. 